\title{
Eski Türkçe ile Yakutçanın Karşılaştırmalı Söz Varlığı: Ünlüyle Başlayan Sözcükler
}

\section{A Comparative Study on Old Turkic and Yakut Vocabularies: Words Starting with Vowels}

\author{
Hülya Y $11 d 1 z^{1}$ (i)
}

Bu makale, Hülya Yıldız, Eski Türkçe ile Yakutçanın Sözvarlı̆̆ının Ünlüyle Başlayan Sözcükler Bakımından Karşılaştırılması, (Basılmamış Doktora Tezi), Yıldız Teknik Üniversitesi Sosyal Bilimler Enstitüsü, İstanbul, 2015 künyeli doktora tezi temel alınarak hazırlanmıștır.

'Dr. Öğr. Üyesi, Anadolu Üniversitesi, Edebiyat Fakültesi, Türk Dili ve Edebiyatı Bölümü, Eskişehir, Türkiye

ORCID: H.Y. 0000-0002-1496-1617

Sorumlu yazar/Corresponding author: Hülya Yıldız,

Anadolu Üniversitesi, Edebiyat Fakültesi, Türk Dili ve Edebiyatı Bölümü, Ofis no: C-303,

Eskişehir, Türkiye

E-mail: hkoprulu@anadolu.edu.tr

Başvuru/Submitted: 08.05.2019

Revizyon Talebi/Revision Requested: 17.06.2019 Son Revizyon/Last Revision Received: 23.06.2019 Kabul/Accepted: 23.06.2019

Online Yayın/Published Online: 28.06.2019

\section{Attf/Citation:}

Yildiz, H. (2019). Eski Türkçe ile Yakutçanın karşılaş̧tırmalı söz varlığı: Ünlüyle başlayan sözcükler. TUDED 59(1), 233-254.

https://doi.org/10.26650/TUDED2019-0010

\section{ÖZET}

Yakutça Ana Türkçe ya da Eski Türkçeye ait eskicil özellikleri en iyi koruyan Türk dillerinden biridir. Yakutça anlambilimi, söz varlığı, söz yapımı ve sesbilgisi açısından diğer Türk dillerine göre daha eskicil olan kimi özellikler barındırır. Diğer çağdaş Türk dillerinde kullanılmayan çok sayıda Eski Türkçe sözcük eskicil anlamlarını koruyarak Yakutçada varlığını sürdürmektedir.

Bu makale VIII.-XIII. yüzyıllar arasını kapsayan Eski Türkçe döneminin Türkçe kökenli söz varlığı ile Yakutçanın söz varlığını karşılaştırmak amacıyla hazırlanmıştır. Ele alınan Eski Türkçe veri, ünlüyle başlayan sözcüklerle sınırlandırılmış ve Yakutçada varlığını sürdüren 60 Eski Türkçe sözcük üzerinde durulmuştur. İncelemenin sonucunda Eski Türkçe adglrlan-, adın, anala-, argur-, aşag, aşla- II, atla-, aytur-, ädgülä-, ädgür-, ädgürt-, ädläş-, ärgür-, erpä-, erpäg, erpäglä-, erpäş-, erpät-, ıdlş-, ıdtur-, ıragu, igidtür-, irklä-, irklät-, irtäş-, ogullan-, ortunkl, ögirt-, ögirtür-, öglän-, $u d l k$, usak, üplän-, üzäki sözcüklerinin günümüzde yalnızca Yakutçada; Eski Türkçe agruk, agtur-, alkan-, artg II, artak, asurt-, atın-, äkäç, ämig, än II, ärlän-, äş- I, ätlän-, ıdala-, içlä-, ilintür-, irtä-, öçäş-, özlä-, udın-, urugla-, ustt-, uzlan-, ükäk, üplä- ve ütläş- sözcüklerinin ise Yakutçayla birlikte birkaç dilde daha varlığını sürdürdüğü gösterilmiştir.

Anahtar Kelimeler: Etimoloji, Söz varlı̆̆ı, Eski Türkçe, Yakutça, Hapax

\section{ABSTRACT}

Yakut is one of the few languages that best preserve Proto Turkic or Old Turkic features. Compared to other Turkic languages, Yakut displays some more archaic features in terms of semantics, vocabulary, word formation and phonology. Many Old Turkic words survive in Yakut with their archaic semantics in the present day.

This article is written in order to compare the vocabulary of Old Turkic to Yakut. Old Turkic data is limited to words whose initial sounds are vowels and in total, 60 words are examined in the study. The results of the study show that the Old Turkic words adgırlan-, adın, anala-, argur-, aşag, aşla- II, atla-, aytur-, ädgülä-, ädgür-, ädgürt-, ädläş-, ärgür-, erpä-, erpäg, erpäglä-, erpäş-, erpät-, ıdış-, ıdtur-, ıragu, igidtür-, irklä-, irklät-, irtäs-, ogullan-, ortunkl, ögirt-, ögirtür-, öglän-, udık, usak, üplän- and üzäki survive only in the current vocabulary of Yakut out of all the Turkic languages. Moreover, it is proven that the Old Turkic words agruk, agtur-, alkan-, artg II, artak, asurt-, atın-, äkäç, ämig, än II, ärlän-, äş- I, ätlän-, ıdala-, içlä-, ilintür-, irtä-, öçäss-, özlä-, udın-, urugla-, usıt-, uzlan-, ükäk, üplä- and ütläş- also survive in Yakut together with a few select other languages.

Keywords: Etymology, Vocabulary, Old Turkic, Yakut, Hapax 


\section{EXTENDED ABSTRACT}

Yakut, or more generally the Siberian Turkic languages, preserve the very old features of the development process of the Common Turkic language. Yakut language is of particular importance for research in comparative historical Turkic linguistics. Accordingly, it is possible to find in the literature a large number of studies which compare the oldest written materials of the Turkic language and Yakut in different respects.

This article is written in order to compare the vocabulary of Old Turkic, known a period lasting from the 8th to 13th centuries, to the vocabulary of the Yakut language. Old Turkic data is limited to those words whose initial sounds are vowels and in total, 60 words are examined in the study. The 60 Old Turkic words in question are as follows: adgtrlan- 'to perform the functions of a stallion; (of mares) acquire a stallion', adın 'other, another', agruk 'heavy baggage and household goods', agtur- 'to raise', alkan- 'to recite praise', anala- 'to call a woman his own mother', argur- 'to tire (someone) out', arlg 'copse, wood, forest, jungle', artak 'spoilt, decaying, putrid', asurt- 'to make someone sneeze', aşag 'eating, food', aşla- II 'to repair', atın- 'to pretend to shoot', atla- 'to ride a horse', aytur- 'to make someone responsible for making the statement with him', ädgülä- 'to find good, to respect highly', ädgür- 'to become healhty', ädgürt- 'to heal, to make healthy', ädläş- 'to esteem or to respect one another', $\ddot{a} k \ddot{a} c ̧$ ' a small girl who displays intelligence and makes herself, as it were, the (elder) sister of the clan', ämig 'nipple, teat; breast, udder', $\ddot{a} \eta$ 'cheek', ärgür- 'to melt, dissolve (something); to macerate', ärlän- '(of a woman) to marry', erpä- 'to saw; to spoil (a business etc.)', erpäg 'a saw', erpäglä- 'to saw', erpäş- 'to saw together', erpät'to give orders for something to be sawn with a saw', äş- I 'to amble', ätlän- 'to put on flesh', ıdala- 'to give up, renounce (something)', ıdış- 'to give something to one another', ıdtur- 'to have (something) sent', ıragu 'song', içlä- 'to line (a garment)', igidtür- 'to have a child nourished and reared', ilintür- 'to long (after sexual pleasure)', irklä- 'to trample on (something $a c c$.$) ', irklät- 'to make (someone dat.) trample on (something acc.)', irtä- 'to$ seek, pursue (something acc.)', irtäşs- 'to scrutinize (something acc.)', ogullan- 'to adopt someone as one's son', ortunkl 'situated in the middle, intermediate', öçäş- 'to be hostile to one another', ögirt- 'to give joy', ögirtür- 'to give joy', öglän- 'to collect one's thoughts; to gain or regain the power to think', özlä- 'to bake (the dough) in the embers', udık 'sleepy, asleep', udın- (a fire, a lamp etc) to die down, to go out', urugla- 'to clean of the seeds', usak 'thirst', usit- 'to make someone thirsty', uzlan- 'to create fine and skilful work in his craft', ükäk 'box; a wall tower on a city wall', üplä- 'to steal', üplän- 'to be plundered', ütläş- 'to be pierced; (of warriors) to smite one another and fight' and üzäki 'situated upon'.

The results of the study show that the Old Turkic words adgirlan-, adın, anala-, argur-, aşag, aşla- II, atla-, aytur-, ädgülä-, ädgür-, ädgürt-, ädläş-, ärgür-, erpä-, erpäg, erpäglä-, erpäşs-, erpät-, ıdış-, ldtur-, ıragu, igidtür-, irklä-, irklät-, irtäş-, ogullan-, ortunkı, ögirt-, ögirtür-, öglän-, udık, usak, üplän- and üzäki survive only in the current vocabulary of Yakut with phonetic and/or semantic changes as atıırdan-, atın, inelee-, triar-, asıl, astaa- I, astaa- 
II, attaa-, lydar-, ütüölee-, ütüör-, ütüört-, ettes-, irier-, erbie- > erbee-, erbii, erbiilee-,

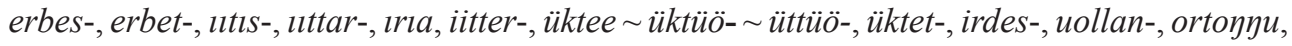
üört-, üörder-, öydön-, utuk, utax, üpten-, and üöseegi, üöseeği, üüseeği, üöseeฑi, üüseeği > $\ddot{u}$ öheeni. These words are the ones which survive only in the current vocabulary of Yakut out of all the Turkic languages.


ärlän-, äş- ätlän-, ıdala-, içlä-, ilintür-, irtä-, öçäş-, özlä-, udın-, urugla-, ustt-, uzlan-, ükäk, üplä- and $\ddot{u} t l a ̈ s ̧-$ have been proven to survive in Yakut with phonetic and/or semantic changes

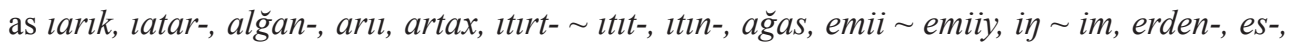
etten-, uttalaa-, istee-, ilinner-, irdee-, ösös- > öhös-, üöstee-, utun-, uruulaa-, utat-, uustan-, ügex, üptee- and üttes-. These words are those which also survive in a few select other Turkic languages with phonetic and/or semantic changes. 


\section{GİRIŞ}

Yakutlar en batıda Ural dağları ve İdil (Volga) nehrinin doğusundan doğuda Altay dağlarına kadar uzanan geniş bir bölgeyi içine alan Sibirya' da yaşayan Türk dilli halklardan biridir (Killi, 1997, s. 57). 3.103.000 km²'lik devasa bir alanı kaplayan Yakutistan, Kuzey Buz Denizi'ne doğru Novosibirsk, batıda Krasnoyarsk, güneyde Amur bölgesi, güneydoğuda Nabarovsk ve doğuda Magadan bölgesiyle çevrilidir (Hayit, 1985, s. 307'den aktaran Killi, 1997, s. 57).

Yakutların Yakutistan'ın yerleşik halklarından biri olmadığı, daha güneydeki bir yerden bugünkü yurtlarına göç ettikleri ${ }^{1}$ üzerine bir görüş birliği vardır (Pakendorf, 2007, s. 7). Yakutların Türkçe konuşan atalarının² büyük bir çoğunluğunun Lena Nehri'nin orta mecralarına XIII.-XIV. yy. dolaylarında göç etmiş oldukları düşünülmektedir (Okladnikov, 1955, s. 326 vd.; Konstantinov, 2003, s. 18 vd.; Alekseyev, 1996, s. 45 vd.'den aktaran Pakendorf, 2007, s. 8). Yakutların göç ettikleri bu bölgede Türk halklarının birbirinden ayrı yaşaması, kavim ilişkilerinin sabit olması, İslam etkisinin olmaması, diğer Türk halklarıyla ilişkilerin zayıf olması, edebî ve yazılı dillerinin gelişmemiş olması gibi etkenler bölgedeki dillerin birtakım eskicil özellikleri korumasını beraberinde getirmiştir (Nasilov, 1997, s. 54). Ortak Türk dilinin gelişim sürecindeki çok eski izleri koruyan Yakutça (Malov, 1952, s. 6; Ubryatova, 1960, s. 2-6; Şirobokova, 1977, s. 108-110'den aktaran Levin, 2001, s. 6) ya da daha genel çerçevede Sibirya Türk dilleri karşılaştırmalı dil tarihi araştırmaları açısından önemli bir inceleme alanı olarak kabul edilmektedir. Buna bağlı olarak literatürde Yakutça ile Türk dilinin en eski yazılı malzemelerinin çeşitli bakımlardan karşılaştırıldığı pek çok çalışmaya rastlamak mümkündür.

Ortak Türk dilinden uzun bir zaman önce ayrılan Yakutçanın Türk dilinin en eski sözlüksel malzemesiyle karşılaştırılması Pekarskiy’in Slovar' yakutskogo yazıka (1917-1928) adlı

1 Yakutların türeyişini anlatan efsanelerde bir zamanlar Baykal bölgesinde yaşayan ve Buryatlar tarafindan sürülen atalarından söz edilmesi, deri kap kacak, kımız ve yağın yapılışı, eyerleme, yükleme, binicilik tarzı gibi noktalar, Yakutçanın söz varlığı (örn. güneye özgü hayvan adları vb.), Yakutların bugün yaşadığı bölgeye güneyden geldiklerini göstermektedir (Killi, 1997, s. 57; Gogolev, 1993, s. 61 ve Konstantinov, 2003, s. 70’ten aktaran Pakendorf, 2007, s. 9).

2 Yakutların ataları, Çin tarihlerinde söz edilen, Baykal Gölü’nün güney Sibirya kıyılarındaki arkeolojik buluntular (VI.-X. yy.) aracılığıyla bilinen Kurıkanlarla özdeşleştirilir (Pakendorf, 2007, s. 7). Runik yazıtlarda Kurıkanlar, Kül Tegin yazıtının doğu yüzünün 4. ve 14. satırlarında anılırlar. 4. satırda 552 yılında ölen Bumın Kağan'ın yoğ törenine katılan halklar arasında Kurıkanların da adları geçer. Bu, Kurıkanların tarihine dair en eski kayıtlardan biridir (Şirobokova, 2005, s. 53-54). A. P. Okladnikov (1949, s. 317) Kurıkanları, Yakutların Lena nehri havzasının güneyi ve Angar'dan X.-XI. yy.'larda Yakutistan'a göç eden Türk kökenli atalarının çekirdeği olarak kabul eder. Baykal bölgesinde geniş bir yayılım gösteren ve VI.-X. yy.'lara tarihlenen bu Demir Çağı kültürünün eski Üç Kurıkan kabile birliğiyle olan bağlantısı ve Batı Buryatlarıyla olan genetik akrabalığı konusunda kuşku yoktur. Ancak Kurıkanların etnik kökeni tartışmalı bir konudur. Bu arkeolojik alanlarda bulunan runik yazıtlardan yola çıkılarak Kurıkanların Türk dilli bir halk olduğu tahmin edilmektedir (Okladnikov, 1955; Konstantinov, 2003; Şirobokova, 1977; Gogolev, 1993; Alekseev, 1996'dan aktaran Pakendorf, 2007, s. 7). Kurıkanların (ya da aralarından bir bölümünün) Türk dili konuştuklarına dair en önemli kanıt, Baykal gölü civarında kayalara ya da kap kacak üzerine runik benzeri işaretlerle yazılmış düzinelerce runik yazıtın varolmasıdır (Şirobokova, 2005, s. 54). 
sözlüğüyle başlamıştır. Bu sözlükte kimi maddebaşlarından sonra Yakutça sözcüğün Eski Türkçe etimolojisine yer verilebildiği görülmektedir. Bundan önce Böhtlingk'in (1851) Yakutça gramerinde Yakutça sözcüklerin Eski Türkçe etimolojilerine değinilmemiş; Radloff'un Opyt slovarya tyurkskih nareçii adlı karş1laştırmalı sözlüğüne Yakutça dahil edilmemiştir ${ }^{3}$. XX. yy.'ın ortalarına gelindiğinde, Ramstedt'in Einführung in die altaische Sprachwissenschaft'inda (1957), Poppe'nin Vergleichende Grammatik'inde (1960) ve Krueger'ın Yakut Manual'ında (1962) yer yer Eski Türkçe-Yakutça sözcük denkliklerine değinildiği görülmektedir. Korkina ve diğ. (1982) ve Kirişçioğlu (1999)'na ait Yakutça gramerlerde de yeri geldikçe Eski Türkçe karşılaştırmalara rastlanabilmektedir.

Literatürde Yakutça sözcüklerin Eski Türkçe etimolojilerine yer veren makaleler ve kitaplar da bulunmaktadır. Şirobokova (1977), Kałużyński (1995), Schönig (1999), Yı1dız (2007b, 2011, 2014) bu gibi makalelerden, Tekin $(1995)^{4}$, Li (1999)5, Levin (2001) Şirobokova $(2001)^{7}$ ise Eski Türkçe ile Yakutça arasında sözlüksel karşılaştırmalar yapan kitaplardan birkaçıdır.

Son yıllarda Eski Türkçenin dönemlerinden birinin söz varlığı ile Yakutçanın sözvarlığını karşılaştırmalı olarak değerlendiren tezler de yapılmış bulunmaktadır. Örneğin Civelek (2006), dindışı Eski Uygurca metinlerin söz varlığı ile Yeni Uygurca, Özbekçe ve Sibirya grubu Türk dillerinin (Tuvaca, Hakasça, Altayca, Yakutça) sözvarlığını karşılaştırmalı olarak incelediği yüksek lisans tezinde din dışı Eski Uygurca metinlerde geçen sözcüklerin en az rastlandığı dilin Yakutça olduğu sonucuna ulaşmıştır. Yıldız (2007a), Orhon Türkçesinin üç büyük yazıtını söz varlığı ve söz yapımı bakımından Yakutça ve Dolganca ile karşılaştırmış ve bu yüksek lisans tezinde Yakutça ve Dolgancada varlığını sürdüren sözcüklerin daha çok Orhon Türkçesindeki yalın adlar ve fiiller olduğunu göstermiştir. Karahan (2010), doktora tezinden kitaplaştırılmış Divanu Lügati't-Türk'e Göre Türk Lehçe Bilgisi adlı eserinde $D L T$ 'deki sözcüklerin Yakutça karşılıklarına da yer vermektedir. Pekacar'ın (2012) yüksek lisans tezinde $D L T$ ' deki kültür sözcükleri ile Yakutçanın söz varlığı karşılaştırılmıştır. Yıldız (2015) ise Eski Türkçe ile Yakutçanın söz varlığı karşılaştırmalı olarak inceleyen bir doktora çalışması hazırlamıştır.

Bu makale, Yıldız’ın (2015) Eski Türkçe ile Yakutçanın Sözvarlığının Ünlüyle Başlayan Sözcükler Bakımından Karşılaştırılması başlığını taşıyan doktora tezi temel alınarak hazırlanmıştır. Söz konusu doktora tezinde Orhon, Yenisey, Eski Uygur ve Karahanlı Türkçelerinin dahil olduğu, VIII.-XIII. yüzyıllar arasında devam eden Eski Türkçe döneminin

3 Radloff, Yakutçayı önce Moğolcalaşmış, sonra Türkçeleşmiş, kökeni belirsiz bir dil olarak kabul etmektedir.

4 Bu kitapta Yakutçada varlığını sürdüren Ana Türkçedeki birincil uzun ünlülü sözcükleri bulmak mümkündür.

5 Bu kitapta Eski Türkçedeki akrabalık adlarının Yakutça karşılıklarını bulmak mümkündür.

6 Adı Orhon Türkçesi ile Yakutçanın Sözcük-Anlambilimsel Koşutlukları (Altayca, Hakasça ve Tuvacayla Karşılaştırmalı Olarak) biçiminde Türkçeye çevrilebilecek olan bu kitapta, Orhon Türkçesinde kök hâlinde bulunan ad ve eylemlerin Yakutça karşılıkları incelenmiştir. Ancak kitaptaki karşılaştırmaların bir bölümü hatalıdır. Bu çalışma Yıldız (2006, s. 177-221) tarafından ayrıntılı olarak değerlendirilmiştir.

7 Bu çalışmada Yakutçanın ünsüzler düzeninin tarihî gelişimi ele alınmaktadır. 
ünlüyle başlayan Türkçe kökenli söz varlığı ile Yakutçanın söz varlığg karşılaştırmalı olarak incelenmiştir. Bu tezde Eski Türkçe maddebaşları için temel referanslar başta Clauson'un An Etymological Dictionary of Pre-Thirteenth-Century Turkish (1972) adlı sözlügü olmak üzere, Röhrborn'un 1977-1998 y1lları arasında yayımlanan Uigurisches Wörterbuch'u ve Erdal'ın Old Turkic Word Formation'ıdır (1991). Yakutça karşılaştırmalar içinse Pekarskiy sözlüğ̈̈ (1917-1928) ile Sleptsov ve diğ. (1972)'e başvurulmuştur. Doktora tezinin sonuçları, değerlendirmeye alınan yaklaşık 2.600 Eski Türkçe sözcükten 2.150 kadarının Yakutçada varlığını sürdürmediğini, Yakutçada varlığını sürdüren sözcüklerin ise 450 kadar olduğunu ortaya koymaktadir.

Makalede Yakutçada tespit edilebilen bu 450 sözcükten günümüzde yalnızca Yakutçada ya da Yakutçayla birlikte birkaç Türk dilinde daha varlığını sürdüren ender söz malzemesi üzerinde durulacaktır. Çalışma üç bölüm olarak tasarlanmıştır: Okumakta olduğunuz Giriş bölümünde Eski Türkçe ile Yakutçanın sözvarlığının karşılaştırıldığı araştırmalar geçmişten günümüze kısaca tanıtılmaktadır. İkinci bölümde Eski Türkçe ile Yakutçanın söz varlığı yukarıda tanımlanan sınırlılık çerçevesinde incelenmekte ve toplam 60 sözcük üzerinde durulmaktadır. Üçüncü ve son bölüm ise elde edilen bulguların özetlendiği sonuç bölümü olarak okuyucunun dikkatine sunulmaktadır.

\section{Eski Türkçe ile Yakutçanın Karşılaştırmalı Söz Varlığı}

İncelemenin bu bölümünde, günümüzde yalnızca Yakutçada ya da Yakutçayla birlikte bir ya da iki dilde varlığını sürdüren ender söz malzemesi üzerinde durulmaktadır.

1. ET adgırlan- 'tay aygırlaşmak; kısrak kendine aygır bulmak' (Clauson, 1972, s. 50a) > Yak. atırdan- 'aygır sahibi olmak' (Pekarskiy, 1917, s. 203).

Eski Türkçede (ET) ilk olarak Divanu Lügati 't-Türk'te (DLT) 'tay aygırlaşmak; kısrak kendine aygır bulmak' anlamlarıyla geçen bu sözcük $D L T$ dışında yalnızca XVI. yy. Osmanlıcasında aygırlan- '(tay) aygırlaşmak' olarak tanıklanabilmektedir (Clauson, 1972, s. 50a). Ancak sözcüğün Yakutçada en azından Pekarskiy dönemine kadar (?) varlığını sürdürmüş olduğu söylenebilir.

2. ET adın 'diğer, başka' (Clauson, 1972, s. 60a; ayr. krş. Röhrborn, 1977, s. 48b) > Yak. atın I '1. değişik, ayrı, başka, farklı, bazı, diğer, yabanc1; 2. fark' (Pekarskiy, 1917, s. 200), ayr. bkz. atın (Sleptsov ve diğ., 1972, s. 52).

Eski Türkçe döneminde ilk olarak Manihaist Uygur metinlerinde görülen adın sözcüğü, Clauson'a göre (1972, s. 60) XIV. yy.'a kadar yaygın olsa da sonraları sözcüğe rastlanmamaktadır. *Ad- fiilinden türediği varsayılan bu sözcük, ET’deki adruk, öyi, özgä ile hemen hemen aynı anlama gelir ve sonradan yerini genellikle Farsça dīgar'a bırakmıştır (Clauson, 1972, s. 60a). Ancak ET adın sözcügüü günümüzde sadece Yakutçada varlığını sürdüren ender sözcüklerden biridir. 
3. ET agruk 'ağır nesne, ağır yük vb.' (Clauson, 1972, s. 90b; ayr. krş. Röhrborn, 1979, s. 74a) > Yak. ıarık 'oldukça ağır' (Pekarskiy, 1928, s. 3748), ayr. bkz. ıarık (Sleptsov ve diğ., 1972, s. 521).

Clauson'un yalnızca DLT ile örneklendirdiği agruk 'ağır yük ve ev eşyaları' sözcüğü agrt- agru- fiilinden türeyen bir somut addır (Clauson, 1972, s. 90b). Bu sözcük daha sonra Eski Uygurcada da tespit edilmiştir. Günümüzde yalnızca (?) XX. yy. Anadolu'sunda ağrık avruk olarak yaşadığı varsayılan (bkz. Clauson, 1972, s. 90b) ET agruk sözcüğünün Yakutçada da tespit edilmesi sözcüğün Anadolu dışında da varlığını sürdürdüğünü ortaya koymaktadir.

4. ET agtur- 'yükseltmek, tırmandırmak, kaldırmak' (Clauson, 1972, s. 82a; ayr. krş. Röhrborn, 1979, s. 76a) > Yak. ıatar- I ' (... $)^{8}$; kaldırmak, çıkarmak, yükseltmek; altından kalkmak; üstün gelmek, hakkından gelmek’ (Pekarskiy, 1928, s. 3752).

İlk olarak Türk dilinin en eski belgelerinden birinde, Tuńukuk Yazıtının 25. satırında kaydedilen bu sözcük, tüm tarihi dönemlerde yaygın olarak kullanılan $a g$ - $I$ fiilinin ettirgen biçimidir (Clauson, 1972, s. 82a). ET agtur- fiili Clauson'a göre yalnızca (?) iki güneybatı dilinde, Türkçe ve Türkmencede $a \breve{g} d \imath r$ - ve $a: g d \imath r$ - biçimleriyle varlığını sürdürmektedir. Clauson'un bu bilgiyi soru işaretiyle kaydetmesi isabetli olmuştur. Çünkü ET agtur- fiilinin Yakutçada da en azından Pekarskiy dönemine kadar (?) kullanılmış olduğu görülmektedir.

5. ET alkan- ‘övmek’ (Clauson, 1972, s. 138b; ayr. krş. Röhrborn, 1979, s. 96a) > Yak. alğan- '1. birisinden hayır dua almak; 2. ululanmak, övgü ve hayranlık konusu olmak; 3. kendisi için dua etmek; seslenmek, dua okumak’ (Pekarskiy, 1917, s. 74).

ET'de ilk olarak Manihaist Uygur metinlerinde kaydedilen alkan- fiili, alka- 'övmek'in dönüşlü çatısı olsa da alka- ile aynı anlamda kullanılmaktadır (Clauson, 1972, s. 138b). Clauson'un soru işareti ile günümüzde yalnızca Tuvacada alğan- 'yalvarıp yakarmak' anlamıyla varlığını sürdürdügüünü belirttiği bu fiilin Pekarskiy dönemine kadar (?) Yakutçada da kullanımda olduğu anlaşılmaktadır.

6. ET anala- 'birisini anas1 yerine koymak' (Clauson, 1972, s. 186b) > Yak. ińelee- '1. birisini bir başkasına anne olarak dayatmak; 2 . birisini annesi bilmek, birisine anne demek; 3 . annesinin yerini almak, birisine annelik etmek, birisine anne ilgisiyle yaklaşmak' (Pekarskiy, 1917, s. 908).

$\mathrm{Bu}$ fiil, ET'de ilk olarak Eski Uygurca döneminde ortaya çıkan ana 'anne' adından türemiştir (Clauson, 1972, s. 169b). Orhon Türkçesinde ise bilindiği gibi ana değil, ög sözcüğü kullanılmaktadır. Günümüzde ana sözcüğü, kimi zaman anne vb. olağandışı ses değişimlerine uğramış olsa da tüm çağdaş dil gruplarında (Clauson, 1972, s. 169b) varlığını

8 Pekarskiy'in latar- I maddesinde verdiği bu anlam, etimolojik olarak ET agtar-fiiiyle bağlantılı olup burada verilmesi hatalıdır. 
sürdürmektedir. Clauson (1972, s. 186b), bu addan türemiş anala-fiilinin sadece DLT'de kaydedilen bir hapax olduğunu belirtmiştir. Ancak fiilin Yakutçada Pekarskiy dönemine kadar (?) ińelee- biçimiyle kullanıldığı ve bu sözcüğün hapax olma niteliğini yitirdiği ortaya çıkmaktadır.

7. ET argur- 'yormak' (Clauson, 1972, s. 218a) > Yak. ırıar- 'güçten düşürmek; çektirmek, bıktırmak, yormak’ (Pekarskiy, 1928, s. 3823), ayr. bkz. ırıar- (Sleptsov ve diğ., 1972, s. 529).

ET döneminde ilk olarak Irk Bitig'de geçen ar- 'yorulmak' fiilinin - $g U r$ - ettirgenlik ekli argur- biçimi Clauson'a (1972, s. 218a) göre DLT’ye özgüdür. ET ar- fiili günümüz Türk dillerinin çoğunda ve genellikle art- aru- şeklinde genişlemiş olarak varlığını sürdürse de ettirgen çatılı ET argur- fiilinin günümüzde korunduğu tek Türk dili Yakutçadadır.

8. ET arıg II 'koru, ağaçlık, orman' (Clauson, 1972, s. 214a; ayr. krş. arıg II, Röhrborn, 1981, s. 188a) > Yak. arı I 'ada; koru; orman adası; kök; ekim alanı, sürülü toprak, çayırlık; nehir yakınında ya da adada bulunan çayırlık; kesili, biçili alan’ (Pekarskiy, 1917, s. 154), ayr. bkz. arı I (Sleptsov ve diğ., 1972, s. 48).

Arıg II 'koru, ağaçlık, orman' sözcüğü, ET'de yış 'dağ ormanı' (Clauson, 1972, s. 976a) ve $l$ : 'çalılık' (Clauson, 1972, s. 1a) ile birlikte, farklı türdeki bitki örtülerini ifade eden birkaç sözcükten biridir. İlk olarak Budist Uygur metinlerinde geçen sözcük, ayrıca aynı anlamdaki simek (Clauson, 1972, s. 829a) ile ikilemeli olarak da kullanılabilmektedir. Clauson (1972, s. 214a), ET arıg II sözcügünün günümüzde yalnızca Hakasça ve Tuvacada varlığını sürdürdügünü bildirse de bu bilgiyi soru işaretiyle kaydetmiştir. Ancak sözcügün Yakutçada da korunduğu görülmektedir.

9. ET artak 'bozulmuş, çürüyen, kokuşmuş’ (Clauson, 1972, s. 204b; ayr. krş. Röhrborn, 1981, s. 207b) > Yak. ardax 'kötü hava, yağmurlu ya da karlı hava; yağmur; 2. küf' (Pekarskiy, 1917, s. 147), ayr. bkz. ardax (Sleptsov ve diğ., 1972, s. 46).

ET artak 'bozulmuş, çürüyen, kokuşmuş’ sözcügünün kökü arta- 'bozulmak, ekşimek, kötüleşmek” (Clauson, 1972, s. 208a) fiilidir. Clauson'a göre ET arta- fiili yalnızca (?) Kaça, Koybal diyalektlerinde Sagayca ve Teleütçede, Hakasçada ve XX. yy. Anadolu'da arda-/ ardl- olarak varlığını sürdürmektedir. ET artak sözcüğünün türediği arta- fiili Yakutçada da ardaa- '(hava) kapanmak, bozmak, kar ya da yağmur yağmak' (Pekarskiy, 1917, s. 146), ayr. bkz. ardaa- (Sleptsov ve diğ., 1972, s. 46) şeklinde tespit edilebilmektedir. Clauson ET artak sözcügünün yalnızca (?) Anadolu'da ardak olarak varlığını sürdürdüğünü belirtmiş olsa da bu sözcük Yakutçada da yukarıda verilen anlamlarıyla kullanılmaktadır.

10. ET asurt- 'hapşırtmak' (Clauson, 1972, s. 251b) > Yak. Itırt- 'hapşırmak' (Pekarskiy, 1928, s. 3852) Itıt- II 'bkz. ıtırt-' (Pekarskiy, 1928, s. 3855), ayr. bkz. Itırt- (Sleptsov ve diğ., 1972, s. 533). 
ET'de ilk olarak DLT' de geçen bu fiil, ilk olarak Eski Uygurcayla tanıklanabilen asur'hapşırmak' (Röhrborn, 1981, s. 236a) fiilinin ettirgen biçimidir. Clauson, Radloff'a dayanarak ettirgen asurt- fiilinin yalnızca Baraba Tatarcasında azırt- olarak varlığını sürdürdüğünü belirtse de bu bilgiyi soru işaretiyle kaydetmektedir. Fakat ET asurt- sözcüğünün Yakutçada da düzenli ses değişimleriyle ıtırt- halinde varlığını sürdürdüğü görülmektedir.

11. ET aşag 'yeme, yiyecek' (Clauson, 1972, s. 259a) > Yak. ası III 'yemek, yiyecek' (Pekarskiy, 1917, s. 176).

ET'de yaygın olarak kullanılan aşa- ‘yemek' fiilinden türemiş addır. ET aşag sözcüğünün Pekarskiy döneminde Yakutçada ası halini aldığ görülmektedir. Daha yeni ve olası *ahı biçimi ise Yakutçanın çağdaş sözlüğünde bulunmamaktadır. Clauson (1972, s. 259a), Radloff sözlüğünde kaydedilen Kırgızca aşaw ve Kazakça asaw biçimlerinin XX. yy. sözlüklerinde bulunmadığını, dolayısıyla sözcüğe ilişkin kayıtların sadece Eski Uygurcadaki biçimler olduğunu yazmaktadır. Buna rağmen ET aşag sözcüğünün Yakutçada anlam değişikliğine uğramadan belli bir döneme kadar (?) varlığını korumuş olduğu anlaşılmaktadır.

12. ET aşla- II 'tamir etmek, onarmak' (Clauson, 1972, s. 262b) > Yak. astaa- '2. işlemek, döşemek, kaplamak’ (Pekarskiy, 1917, s. 1739).

ET'de ilk olarak DLT'de kaydedilen 'tamir etmek" anlamlı fiil, daha sonraki yazı dillerinden yalnızca XIV. yy. Kıpçakçasında geçmiş nadir bir veridir. Bu fiil Yakutçada belli bir döneme kadar (?) varlığgnı sürdürmüştür.

13. ET atın- 'ok atmış gibi yapmak' (Clauson, 1972, s. 61b) > Yak. Itın- II 'kendini vurmak’ (Pekarskiy, 1928, s. 3851), ayr. bkz. Itın- II (Sleptsov ve diğ., 1972, s. 533).

İlk olarak $D L T$ 'de geçen bir veri olup daha sonraki tarihi dillerde tanıklanamamıştır. Clauson'un soru işaretiyle yalnızca Hakasçada atın- 'kendini vurmak' ve Kazan Tatarcasında atın- 'salıncakta sallanmak' olarak varlığını sürdürdüğünü yazdığı bu sözcük Yakutçada ıtınolarak kullanılmaktadır. Clauson'un bu maddede verdiği Tuvaca attın- 'vurulmak' fiili ise ET atın-'in değil, Yakutçada da ıtılın- I 'kendini öldürmek, silahla intihar etmek' (Pekarskiy, 1928, s. 3850) olarak varlığını sürdüren *atlın- (<*atılın-) fiilinin devamı olduğu için hatalidir.

14. ET atla- 'ata binmek' (Erdal, 1991, s. 431; Röhrborn, 2010, s. 102) > Yak. attaa- '1. at çağırmak; 2. at temin etmek; 3. koymak, hafifletmek, iğdiş etmek, enemek, kurtarmak' (Pekarskiy, 1917, s. 194), ayr. bkz. attaa- II (Sleptsov ve diğ., 1972, s. 52).

Eski Uygurcanın sadece bir metninde geçen bu ender sözcük, Eski Türkçede daha sık tanıklanabilen atlan- 'ata binmek' ve atlantur- 'ata bindirmek' fiillerinin tabanıdır. ET atlafiili günümüzde yalnızca (?) Yakutçada varlığını sürdürüyor görünmektedir.

9 Pekarskiy'in astaa- maddesinde verdiği bu anlam, aslında ET aş II'den türeyen aşla- II fiiliyle ilişkili olduğu için çalışmamızda aşla- II başlığı altında değerlendirilmiştir. 
15. ET aytur- 'söyletmek' (Clauson, 1972, s. 269b) > Yak. 1ydar- 'emir almak' (Pekarskiy, 1928, s. 3764), ayr. bkz. ıydar- (Sleptsov ve diğ., 1972, s. 523).

ET ay- fiilinin ettirgen biçimi olan (Clauson, 1972, s. 269b) bu sözcük ilk olarak DLT'de, sonrasında ise XIV. yy. Kıpçakçasında geçmektedir. ET aytur- fiili günümüzde yalnızca Yakutçada varlığını sürdürmektedir. Çünkü tüm çağdaş dil gruplarında görülen aytturbiçimi, daha geç dönemde ortaya çıkan anlamlarıyla ayıt- fiilinin ettirgeni olup (Clauson, 1972, s. 269b) ET aytur- fiilinin devamı değildir.

16. ET ädgülä- 'iyi bulmak, takdir etmek' (Röhrborn, 1994, s. 351b) > Yak. ütüölee- II 'hürmet göstermek' (Pekarskiy, 1928, s. 3200).

İlk olarak Eski Uygurca döneminde ortaya çıkan bu fiil, ädgü sözcüğünden $+l A$ - ekiyle türemiştir. Bu fiilin ses ve anlam değişimiyle Yakutçada en azından XX. yy.'a kadar (?) varlığını sürdürdüğü görülmektedir.

17. ET ädgür- 'iyileşmek, sağlı̆̆ına kavuşmak' (Röhrborn, 1994, s. 355b) > Yak. ütüör'sağlığına kavuşmak, iyileşmek, şifa bulmak, sağalmak; hastalıktan kurtulmak, hastalığı atlatmak’ (Pekarskiy, 1928, s. 3201), ayr. bkz. ütüör- (Sleptsov ve diğ., 1972, s. 459).

ET ädgü gövdesinden durum değişimi bildiren $+r$ - ekiyle türeyen bu fiil, ilk olarak Eski Uygurcada ve yalnızca Hsüan-tsang metninde geçer. Bu fiilin Yakutçada anlam değişimine uğramadan günümüze kadar geldiği görülmektedir.

18. ET ädgürt- 'iyileştirmek, güçlendirmek' (Röhrborn, 1994, s. 355b) > Yak. ütüört'iyileştirmek, tedavi etmek, sağaltmak, otamak' (Pekarskiy, 1928, s. 3202), ayr. bkz. ütüört(Sleptsov ve diğ., 1972, s. 459).

İlk olarak Eski Uygurcada ve yalnızca Hsüan-tsang metninde geçen ädgür- 'iyileşmek, sağlığına kavuşmak' (Röhrborn, 1994, s. 355b) fiilinin ettirgenlik çatısı olan bu fiil de yalnızca Hsüan-tsang aracılığıyla tanıklanabilen verilerden biridir. Fiil günümüzde yalnızca Yakutçada varlığını sürdürmektedir.

19. ET ädläş- 'birbirine sayg1 duymak' (Clauson, 1972, s. 58b) > Yak. ettes- '2 . birisinin hayvanlarını ya da mallarını geçici bir süre kullanmak için almak (kiralamak)' (Pekarskiy, 1917, s. 319) ${ }^{10}$, ayr. bkz. ettee- ‘4. kiraya vermek’11 (Sleptsov ve diğ., 1972, s. 549).

ET'de 'bir şeyi yararlı hale dönüştürmek; işlemek, ekip biçmek (bahçe vb.); yararlı görmek, yararına inanmak; (birisine) değer vermek, saygı duymak; yapmak, yaratmak' kaydedilen ädlä- fiili günümüzde bazı Türk dillerinde varlığını sürdürür (Clauson, 1972, s. 57a). Bunun işteşlik çatısı olan ädläşs- fiili ise Clauson tarafından ET'de ilk ve son olarak

10 Pekarskiy burada kökeni ET etle:-'ye giden Yak. ettes- sözcüğ̈̈ ile kökeni ET edlleş-'e giden Yak. ettessözcüklerini karıştırmıştır.

11 Yak. ettee- maddesinde dördüncü anlam olarak verilen bu sözcük ET etle-fiiliyle değil, ET ed lle-fiiliyle ilişkilidir. 
DLT' de geçen bir hapax olarak verilmiştir. Ancak ET ädläş- fiili Yakutçayla da tanıklabildiği için hapax olma niteliğini yitirmektedir.

20. ET äkäç 'zeka gösterip kendini bir boya abla gibi kabul ettiren küçük k1z' (Clauson, 1972, s. 102a) > "Yak. (S) ağas 'abla; baba tarafından yaşça küçük kadın akraba' Yak. (B) ăgas 'abla', Yak. (P) ăgas '1) yaşça büyük (kadın); (söyleyenin cinsiyeti ile ilgili olmaksızın) baba tarafından yaşça büyük kadın akraba: a) abla; b) kuzin (amca kızı); babanın amcasının oğlunun kızı; ç) hala; d) babanın kuzini; e) babanın halası” (Li, 1999, s. 174).

Clauson'un Etimolojik Sözlük'ü yayımladığı dönemde yalnızca $D L T$ ile tanıklanabilen +ç küçültme ekli äkäç sözcügü bu kaynakta hapax olarak verilmiştir. Ancak daha sonra sözcüğün Eski Uygurcada da geçtiği ortaya çıkmıştır (bkz. Röhrborn, 1994, s. 362b). Üstelik Türkmence (ağ.) egeç, Karaçay-Balkarca egeç, Tatarca (ağ.) igeç (Li, 1999, s. 172-174)12 verileri de ET äkäç sözcüğünün devamıdır. DLT dışında Eski Uygurca, Yakutça ve başka Türk dilleriyle tanıklanabilen ET äkäç sözcüğünün bu durumda hapax olma niteliğini yitirdiği görülmektedir.

21. ET ämig 'meme başı, meme ucu, emzik; meme, göğüs, hayvan memesi' (Clauson, 1972, s. 158b; ayr. krş. Röhrborn, 1998, s. 376a) > Yak. emii emiiy 'kadın memesi; gögüu, meme ucu' (Pekarskiy, 1917, s. 256), ayr. bkz. emiiy (Sleptsov ve diğ., 1972, s. 539).

Clauson ET ämig sözcüğünü yalnızca Eski Uygurca ve $D L T$ ile örneklendirmiş, sözcüğün günümüzde yalnızca (?) Tuvacada yaşadığını, başka yerlerde bu sözcügün yerini emçek'in aldığı belirtmiştir. Pekarskiy (1917, s. 256) ise emii, emiiy maddesinde sözcüğü Koybalca emey ve Soyotça emiğ ile karşılaştırmıştır. Bu durumda ET emig sözcüğü Tuvaca, Yakutça, Koybalca ve Soyotçada varlığını sürdürmektedir.

22. ET äy II 'yanak; ten rengi’ (Clauson, 1972, s. 166a; ayr. krş. Röhrborn, 1998, s. 381a) > Yak. in 'elmacık kemiği, yanak; allık, kırmızılık' (Pekarskiy, 1917, s. 942), im I 'ay.' (Pekarskiy, 1917, s. 931), ayr. bkz. in (Sleptsov ve diğ., 1972, s. 152).

Clauson'da ilk olarak DLT ile örneklendirilen; fakat ondan önce Eski Uygurcada da geçtiği ortaya çıkan $\ddot{a} \eta$ II sözcüğü Türk dilinin tarihi dönemlerinde yaygın olarak kullanılmıştır. Clauson (1972, s. 166a) bu sözcüğün modern kaynaklardan sadece Şemseddin Sami’nin Kamus-ı Türkî'sinde kayıtlı olduğunu ve orada bile 'eski’ olarak nitelendirildiğini belirtmiş, başka bir Türk diline gönderme yapmamıştır. Fakat ET äy II sözcügünün ET’deki anlamlarını koruyarak Yakutçada varlığını sürdürdüğü görülmektedir.

23. ET ärgür- 'eritmek' (Clauson, 1972, s. 227a; ayr. krş. Röhrborn, 1998, s. 426b) > Yak. irier- 'eritmek, çözdürmek, erimesi için ısıtmak, donmuş bir şeyi yumuşatmak' (Pekarskiy, 1917, s. 956), ayr. bkz. irier- (Sleptsov ve diğ., 1972, s. 154).

12 Bu biçimler Li (1999, s. 172-174)'deki äkä maddesinde ele alınmış olsa da aslında ET äkäç sözcügünün devamidır. 
ET'de ilk olarak Manihaist Uygur metinlerinde, daha sonra ise DLT'de geçen bu fiil - $g U r$ - ekiyle türetilmiş ettirgen bir gövdedir. Günümüz Türk dillerinde 'eritmek' anlamında ET ärüt- fiilinden gelişen biçimler kullanılırken (Clauson, 1972, s. 207b) Yakutça ET ärgürfiilini fonetik değişimle yaşatmaya devam eden tek Türk dilidir.

24. ET ärlän- '(kadın) evlenmek” (Clauson, 1972, s. 230b) > Yak. erden- '1. (kadın) evlenmek; 2. (kadın) cinsel ilişkide bulunmak’ (Pekarskiy, 1917, s. 296), ayr. bkz. erden(Sleptsov ve diğ., 1972, s. 545).

ET'de ilk olarak $D L T$ 'de geçen bu dönüşlü fiil gövdesi Clauson'a (1972, s. 230b) göre günümüzde yalnızca (?) Kırgızcada erden- erlen- 'erkeklik göstermek, olgunlaşmak' olarak varlığını sürdürmektedir. Ancak sözcük Yakutçada erden-, Hakasçada irlen- '1. kocaya varmak; 2. yiğitlenmek, erkeklenmek’ (Arıkoğlu, 2005, s. 225) biçimiyle tespit edilebilmektedir.

25. ET erpä- 'testereyle kesmek; daha iyisini yapabilmek için bir işi bozmak' (Clauson, 1972, s. 199a) > Yak. erbie- 'testereyle kesmek; kesmek, biçmek' (Pekarskiy, 1917, s. 287), ayr. bkz. erbee- (Sleptsov ve diğ., 1972, s. 543).

Clauson'un ET döneminde yalnızca DLT'de geçen bir hapax olarak verdiği sözcük Pekarskiy dönemi Yakutçasında erbie-, daha geç dönemde erbee-olarak tespit edilebilmektedir. Günümüzde yalnızca Yakutçada varlığını sürdürmekte olan bu fiil Yakutçayla tanıklanabildiği için hapax olma özelliğini yitirmiştir.

26. ET erpäg 'testere' (Erdal, 1991, s. 176) > Yak. erbii '1. erbie- 'testereyle kesmek' fiilinin hareket adı; 2. testere’ (Pekarskiy, 1917, s. 287), ayr. bkz. erbii (Sleptsov ve diğ., 1972, s. 543).

ET'de yalnızca Maitrisimit metninde geçen bu araç adı Yakutçada erbii şeklinde ve aynı anlamda varlığını sürdürmektedir. ET erpäg sözcüğünün günümüzde yalnızda Yakutçada korunduğu görülmektedir.

27. ET erpäglä- 'testereyle kesmek' (Erdal, 1991, s. 437) > Yak. erbiilee- 'testereyle kesmek’ (Pekarskiy, 1917, s. 287).

Erdal (1991, s. 437) ET erpeg adından türeyen bu ET fiili erpäKlä- biçiminde yazmıştır. Ancak sözcüğün Yakutçada erbii+lee- biçiminde yaşıyor olması ikinci hece sonundaki ünsüzün *- $k$ değil, - $g$ olduğunu gösterir. Ayrıca Erdal'ın hapax olarak verdiği sözcük Yakutça aracılığıyla tanıklanabildiği için bu niteliğini yitirmiştir.

28. ET erpäş- (Erdal, 1991, s. 557) > Yak. erbes- 'erbee- Fi. Bir.-İşt. Bi.' (Sleptsov ve diğ., 1972, s. 543).

Erdal, ET'de sadece Maitrisimit metninde geçen bir hapax olarak değerlendirdiği bu fiilin geçtiği cümlenin çevirisini yapmamış ve fiilin anlamını vermemiştir. ET erpä- 'testereyle 
kesmek' fiilinin işteşlik çatısı olan erpäş- fiili 'birlikte testereyle kesmek' anlamındadır. Sleptsov ve diğ.' de (1972, s. 543) yalnızca “erbee- Fiilinin Birliktelik-İşteşlik Biçimi” anlamına gelen bir kısaltmayla verilen erbes- fiilinin Pekarskiy döneminde kayda geçmemiş olması ilginçtir. ET erpäşs- fiili Yakutçada tespit edilebildiği için hapax olma niteliğini yitirmektedir.

29. ET erpät- 'testereyle kestirmek' (Clauson, 1972, s. 199b) > Yak. erbet- '(saç) kestirmek’ (Pekarskiy, 1917, s. 286), ayr. bkz. erbet- (Sleptsov ve diğ., 1972, s. 543).

ET'de ilk ve son olarak DLT' de geçen ve Clauson tarafindan hapax kaydiyla verilen bu ettirgen fiil Yakutçada varlığını sürdürmekte ve bu nedenle hapax olma özelliğini yitirmiş bulunmaktadır.

30. ET äş- I 'yavaş yavaş dolaşmak, rahvan koşmak' (Clauson, 1972, s. 255b) > Yak. is- II 'hareket etmek, ilerlemek, yürümek, ağır ağır yürümek, seğirtmek, gitmek' (Pekarskiy, 1917, s. 961), ayr. bkz. is- I (Sleptsov ve diğ., 1972, s. 154).

Clauson (1972, s. 255b) ET'de ilk olarak Irk Bitig'de geçen bu fiilin günümüzde yalnızca Türkçede 'acele etmek' anlamıyla varlığını sürdürdüğünü belirtmiştir. Ancak ET äş- I fiili Yakutçada da varlığını sürdürmektedir.

31. ET ätlän- 'şişmanlamak' (Clauson, 1972, s. 58b) > Yak. etten- 'etli olmak, (sı̆̆ır) semiz olmak; balık etli olmak, etli butlu olmak, tecessüm etmek, ete kemiğe bürünmek, kendine cismanî bir görünüş vermek' (Pekarskiy, 1917, s. 319), ayr. bkz. etten- (Sleptsov ve diğ., 1972, s. 549).

Clauson'un soru işaretiyle yalnızca Hakasça itten- kaydıyla yer verdiği bu sözcük Yakutçada etten-, Türkçede etlen- 'şişmanlamak, semirmek' (Türkçe Sözlük, 2005, s. 663) olarak varlığını sürdürmektedir.

32. ET ıdala- 'bırakmak, vazgeçmek' (Clauson, 1972, s. 59b) > Yak. ıtalaa- 'sırasıyla sonuna kadar bırakmak; azar azar bırakmak, salıvermek, azar azar yollamak' (Pekarskiy, 1928, s. 3841), ayr. bkz. IItalaa- (Sleptsov ve diğ., 1972, s. 534).

Clauson ET'de Budist Uygur metinlerine özgü olan bu nadir fiilin morfolojisinin belirsiz olduğunu, daha çok tit- I ile birlikte kullanıldı̆̆ını ve Tuvacadaki ıdala- 'göndermek, yollamak' biçiminin bu fiilin devamı olabileceğini belirtmiştir. ET ıdala- fiilinin Tuvaca dışında Yakutçada da varlığını sürdürdüğü anlaşılmaktadır.

33. ET ıdış- 'karşılıklı göndermek; göndermekte yarış etmek' (Clauson, 1972, s. 73a) > Yak. utıs- '(birbirlerine karşı olan hatalarını) karşılıklı olarak bağışlamak' (Pekarskiy, 1928, s. 3854).

ET'de ilk olarak $D L T$ 'de görülen bu fiil Clauson tarafından bir de XV. yy. Kıpçakçası ile örneklendirilmiş ve hiçbir çağdaş dile gönderme yapılmamıştır. Ancak ET'nin nadir verilerinden biri olan bu fiilin Yakutça aracılığıyla tanıklanabildiği görülmektedir. 
34. ET ıdtur- 'göndermek' (Erdal, 1991, s. 804) > Yak. nttar- 'ıtt- Fi. Ett. Bi.' (Pekarskiy, 1928, s. 3844; Sleptsov ve diğ., 1972, s. 534).

Erdal (1991, s. 804) Drevnetyurkskiy slovar' (DTS) ve Clauson'un etimolojik sözlüğünde (EDPT) yer almadığını belirttiği bu sözcüğü Eski Uygurca döneminden iki veriyle örneklendirmektedir. Eski Türkçenin nadir verileri arasında yer alan bu ettirgen fiil Yakutçada varlığını sürdürmektedir.

35. ET ıragu 'şarkı' (Erdal, 1991, s. 97) > Yak. ırıa 'şarkı, şarkı söyleme, ötme; milli marş; Zebur; methetme' (Pekarskiy, 1928, s. 3823), ayr. bkz. ırıa (Sleptsov ve diğ., 1972, s. 529).

ET ır 'şarkı' kökünden $+A g U$ topluluk ekiyle türemiş olan bu ad (Erdal, 1991, s. 97) Yakutçada eski ve yeni anlamlarla varlığını sürdürmektedir. Burada ET /AgU/ ses öbeğinin Yakutçada ilk hecedeki /1/ ünlüsüne bağlı olarak /1a/ halini aldığ1 görülmektedir. Yakutça ET ıragu sözcügünü fonetik değişimle yaşatan tek Türk dilidir.

36. ET içlä- '(bir giysiyi) astarlamak' (Clauson, 1972, s. 27a) > Yak. istee- 'giysinin içine astar dikmek (özellikle kürk astar), giysiyi astarlamak’ (Pekarskiy, 1917, s. 973), ayr. bkz. istee- (Sleptsov ve diğ., 1972, s. 155).

Clauson'un soru işaretiyle yalnızca Baraba Tatarcasında etsle-, Tuvacada işte- olarak varlığını sürdürdüğünü belirttiği bu fiil Yakutçada da tespit edilmiştir.

37. ET igidtür- '(çocuğu) beslemek' (Erdal, 1991, s. 804) > Yak. iitter- 'yedirmek' (Pekarskiy, 1917, s. 987), ayr. bkz. iitter- (Sleptsov ve diğ., 1972, s. 144).

Erdal, $D T S$ ve EDPT’ye dahil edilmediğini belirttiği bu veriyi yalnızca Eski Uygurcada ve bir kez geçen bir hapax olarak vermiştir. Bu ettirgen gövdenin Yakutçada anlam değişimine uğramadan kullanıldığı görülmektedir.

38. ET ilintür- '(cinsel zevkten sonra özlem duygusuna) kendini kaptırmak; birisini tuzağa düşürmek' (Clauson, 1972, s. 150a) > Yak. iilinner- 'iilin- Fi. Ett. Bi.' (Pekarskiy, 1917, s. 926).

Bu fiili Türkische Turfan-Texte VIII ve Codex Comanicus ile örneklendiren Clauson (1972, s. 150a), soru işaretiyle fiilin yalnızca Karaycada ilindir- 'başını derde sokmak, tuzağa düşmek' olarak görüldüğünü belirtmiştir. Pekarskiy (1917, s. 926), Yakutçada iilinner- olarak varlığını sürdüren bu fiili "iilin- Fiilinin Ettirgen Biçimi” anlamına gelen bir kısaltmayla vermiştir. Yakutça iilin- II fiili ise ‘bağlanmak (?), takılmak' (Pekarskiy, 1917, s. 926) anlamlarındadır.

39. ET irklä- 'çiğnemek, ayakla ezmek' (Clauson, 1972, s. 226b) > Yak. üktee-, üktüö-, üttüö- 'ayak basmak, girmek, (feribota) binmek; bir şeye basmak, üstüne basmak' (Pekarskiy, 1928, s. 3112), ayr. bkz. üktee- (Sleptsov ve diğ., 1972, s. 451). 
ET'de ilk olarak DLT' de geçen irklä-sözcüğü Yakutçada üktee-, üktüö-, üttüö- biçimleriyle varlığını sürdürmektedir. Yakutça, $D L T$ ’ deki bu fiili günümüzde yaşatan tek Türk dilidir.

40. ET irklät- 'çiğnetmek, ayakla ezdirmek' (Clauson, 1972, s. 227a) > Yak. üktet- 'ükteeFi. Ett. Bi.' (Pekarskiy, 1928, s. 3114), ayr. bkz. üktet- (Sleptsov ve diğ., 1972, s. 451).

Pekarskiy sözlüğünde "üktee- Fiilinin Ettirgen Biçimi” anlamına gelen bir kısaltmayla yer verilen üktet- fiili, DLT' deki irklät- fiilinin devamıdır. Yakutça üktee- fiilinin anlamları yukarıda 2.39' da verilmiştir. DLT' deki ettirgen irklät- fiili de günümüzde yalnızca Yakutçada fonetik değişimle varlığını sürdürmektedir.

41. ET irtä- 'aramak, izini sürmek, peşine düşmek' (Clauson, 1972, s. 208a) > Yak. irdee'incelemek, denemek, araştırmak, çözümlemek, gözden geçirmek (bir işi), tahkikat yapmak, aramak, arayıp bulmak; (adaletin) peşine düşmek; takip etmek, iz peşine düşmek, uğramak, izini aramak, (köpek) iz sürmek' (Pekarskiy, 1917, s. 954) irdie- 'bkz. irdee-' (Pekarskiy, 1917, s. 955), ayr. bkz. irdee- (Sleptsov ve diğ., 1972, s. 153).

ET'de ilk olarak $D L T$ ' de geçen bir veridir. Clauson'un soru işaretiyle yalnızca Anadolu'da irde- olarak korunduğunu belirttiği bu fiil Yakutçada da eski anlamlarıyla varlığını sürdürmektedir.

42. ET irtäş- 'araştırmak' (Clauson, 1972, s. 211a) > Yak. irdes- 'birlikte araştırmak, iz sürmeye yardım etmek’ (Pekarskiy, 1917, s. 955), ayr. bkz. irdes- (Sleptsov ve diğ., 1972, s. 153).

Clauson (1972, s. 211a) ET döneminde yalnızca DLT ile tanıklanabilen bu fiil için hiçbir çağdaş dile gönderme yapmamıştır. Ancak fiilin Yakutçada Eski Türkçedeki anlamıyla korunduğu görülmektedir.

43. ET ogullan- 'evlat edinmek' (Nadelyayev vd., 1969, s. 364) > Yak. uollan- 'oğul sahibi olmak’ (Pekarskiy, 1928, s. 3034), ayr. bkz. uollan- (Sleptsov ve diğ., 1972, s. 437).

EDPT'de yer verilmeyen bu fiil, DTS'de yalnızca Eski Uygurca bir veriyle örneklendirilmiştir. Erdal (1991, s. 514) sözcüğün hapax olduğunu belirtmektedir. Ancak bu sözcük Yakutça ile tanıklanabildiği için hapax olma niteliğini yitirmiştir.

44. ET ortunkı 'ortadaki, ortanca' (Clauson, 1972, s. 212b) > Yak. ortoynu 'ortasında bulunan, ortasindaki' (Pekarskiy, 1927, s. 1876).

Clauson'un yalnızca Eski Uygurca Altun Yaruk'ta geçen bir hapax olarak verdiği bu sözcük Yakutçada anlam değişimine uğramadan varlığını sürdürmektedir. Yakutçayla tanıklanabilen bu ET veri hapax olma özelliğini yitirmiştir.

45. ET öçäş- I 'birbirine düşman olmak', öçäş- II 'bahse tutuşmak' (Clauson, 1972, s. 32a) > Yak. ösös- II '1. birine düşman olmak, yakınmak, söylenmek; kaba konuşmak; 
2. direnmek, inat etmek, ayak diremek, karşı gelmek, bir şeyi kasten yerine getirmemek, yapmamak' (Pekarskiy, 1927, s. 1976) > ayr. krş. öhös- (Sleptsov ve diğ., 1972, s. 290).

Clauson'un (1972, s. 32a) iki ayrı madde olarak ele aldığı bu ET veriler aslında Erdal'ın (1991, s. 564) belirttiği gibi aynı fiilin farklı anlamlarıdır. ET'de ilk olarak Manihaist Uygur metinlerinde geçen ve daha sonraki metinlerde de örneklerine rastlanan bu fiil Clauson'da hiçbir çağdaş dille örneklendirilmemiştir. Ancak sözcüğün Yakutçada ösös- > öhös- biçimleriyle tespit edilebildiği görülmektedir. Ayrıca Clauson’un gözden kaçırdığı Kırgızca öçöş- ‘kin beslemek, hırslanmak, kızmak' (Yudahin, 1998, s. 607) verisi de buraya eklenmelidir.

46. ET ögirt- 'sevindirmek' (Nadelyayev ve diğ., 1969, s. 380) > Yak. üört- 'sevindirmek' (Pekarskiy, 1928, s. 3154), ayr. bkz. üört- (Sleptsov ve diğ., 1972, s. 455).

EDPT'ye dahil edilmeyen bu veri DTS' de sadece Altun Yaruk ile örneklendirilmiştir. ET ögir- fiilinin - $t$ - ekli bu ettirgen çatısının Yakutçada üört- biçiminde varlığını sürdürdüğü anlaşılmaktadır.

47. ET ögirtür- 'sevindirmek' (Erdal, 1991, s. 828) > Yak. üörder- 'sevindirmek, memnun etmek' (Pekarskiy, 1928, s. 3153).

ET ögir- fiilinin - $t U r$ - ekli ettirgen çatısıdır. Erdal (1991, s. 828) bu sözcüğe ögirttürmaddesi içinde değinmekte ve ögirtür- fỉilinin sadece birkaç ET metinde geçtiğini belirtmektedir. DTS ve EDPT'de ET ögirtür- verisi yer almamaktadır. Ancak bu nadir ET fiilin Yakutçada varlığını sürdürdüğü görülmektedir.

48. ET öglän- 'aklını toplamak; aklı başına gelmek, akıllanmak' (Clauson, 1972, s. 107b)

$>$ Yak. öydön- '1. kendine gelmek, aklı yerine gelmek, hafızası yerine gelmek, aklı başında olmak, akıllanmak, bilinci yerine gelmek (baygınlıktan sonra), ayılmak; 2. anlaşılmak, kastedilmek; inandırılmak; anlamak' (Pekarskiy, 1927, s. 1917), ayr. bkz. öydön- (Sleptsov ve di.̆., 1972, s. 283).

ET ög II 'akıl' sözcüğünden türetilen ve yalnızca XIV. yy. Osmanlıcasında geçen ögläfiilinin dönüşlü biçimidir (Clauson, 1972, s. 107b). Clauson ET öglän- fiilini de en son XIV. yy. Osmanlıcasıyla örneklendirmekte ve hiçbir çağdaş dile gönderme yapmamaktadır (bkz. 1972, s. 107b). Ancak ET öglän- fiilinin Yakutçada öydön- olarak varlığını sürdürdüğü görülmektedir. ET öglän- fiilinin gövdesi olan öglä- fiili de Yakutçada öydöö- '1. hatırlamak, hatırından çıkarmamak, biri aklına gelmek; fark etmek, farkına varmak, bir şeye dikkat etmek; 2. anlamak, kavramak, idrak etmek, aklı ermek, kulak vermek, bilmek, sezmek, hissetmek' (Pekarskiy, 1927, s. 1916), ayr. bkz . öydöö- (Sleptsov ve diğ., 1972, s. 283) şeklinde korunmuş bulunmaktadır.

49. ET özlä- '(közde) pişirmek' (Clauson, 1972, s. 287b) > Yak. üöstee- I 'aortu kesmek' (Pekarskiy, 1928, s. 3160). 
Clauson'un soru işaretiyle yalnızca Türkçede özle- 'istemek' olarak varlığını sürdürdüğünü belirttiği ET özlä- sözcüğü Yakutçada da üöstee- şeklinde tespit edilebilmektedir. ET özläfiilinin türediği $\ddot{o z} I$ sözcüğünün 'temelde maddi bedene karşıt olarak insanın varlığının manevi tarafi; kendi; bir canlının iç bölümleri, öz’ vb. anlamları vardır (bkz. Clauson, 1972, s. 278a). Bu sözcük Yakutçada üös I halini almış ve '1. merkez, orta nokta, orta; 2. (ağaç için) öz; 3. (... $)^{13}$; 4. ana kan damarı, kalın hayati damar (aort); kemerin ucu' (Pekarskiy, 1928, s. 3155) anlamlarını kazanmıştır. Yakutçada üös +tee- fiilinin, üös sözcüğüne ait daha özgül 'aort, atardamar' anlamıyla bağlantılı olduğu anlaşılmaktadır.

50. ET udık 'uykulu, mahmur' (Clauson, 1972, s. 46b) > Yak. utuk 'uyku sersemliği, mahmurluk' (Pekarskiy, 1928, s. 3198).

ET udık sözcüğü EDPT'de Manichaica III, Türkische Turfantexte VIII, Budist Uygur metinleri, DLT ve Kutadgu Bilig ile örneklendirilmiştir. Erdal (1991, s. 252), Clauson’un verdiği Manichaica III 9,6-8 ve Kalyanamkara Papamkara 17,1 örneklerinin odug şeklinde düzeltilmesi gerektiğini belirtmektedir. $D T S$ 'de ise $u d \imath k$ sözcüğüne ait ilk veri DLT'den başlamakta, TT VIII'deki doğru örnek bu maddeye dâhil edilmemektedir. ET döneminde yalnızca birkaç metinle tanıklanabilen bu nadir sözcüğün Yakutçada korunduğu görülmektedir.

51. ET udın- '(ateş, lamba) sönmek' (Clauson, 1972, s. 62a) > Yak. utun- 'uykuya dalmak' (Pekarskiy, 1928, s. 3099).

ET döneminde ilk olarak $D L T$ 'de geçen $u d \imath n$ - fiili, $u d l$ - fiilinin mecaz anlamından türetilmiştir. ET udın- fiili Clauson'da soru işaretli olarak yalnızca XX. yy. Türkçe uyun'sessizce uyumak, uyumaya gitmek' kaydıyla örneklendirilmiştir. Bu türetim ET udv-fiilinin mecaz anlamıyla değil, birincil anlamıyla ilişkilidir. Yak. utun- için de aynısı söz konusudur.

52. ET urugla- 'çekirdeğini çıkarmak' (Clauson, 1972, s. 220a) > Yak. uruulaa- '1. bir kimseyi akrabalığa almak, biriyle dünür olmak; 2. düğünü yapılmak’ (Pekarskiy, 1928, s. 3071), ayr. bkz. uruulaa- (Sleptsov ve diğ., 1972, s. 442).

ET'de 'tohum, çekirdek, tane; döl, soy, nesil' gibi anlamları bulunan urug II (Clauson, 1972, s. 214b) adından türemiş fiildir. Clauson'un yalnızca (?) güneydoğu grubu için 'tohum ekmek; oğul vermek; (ekin) başak vermek' anlamlarıyla verdiği bu fiil Yakutçada da kurallı fonetik değişimlerle varlığını sürdürmektedir.

53. ET usak 'susuzluk, susamışlık' (Clauson, 1972, s. 245a) > Yak. utax 'susama, susuzluk; içme (susuzluğu gidermek için), içecek’ (Pekarskiy, 1928, s. 3096), ayr. bkz. utax I (Sleptsov ve diğ., 1972, s. 446).

13 Buradaki '3. nehir ya da gölün ortası; nehir yatağı, seyir koridoru; ırmak kolu, çay, boğaz, kaynak, ırmak kolu’ anlamı öz I (Clauson, 1972, s. 278a) ile değil, öz II (Clauson, 1972, s. 278a) ile ilişkili olduğundan çalışmamızda $\ddot{o} z$ II maddebaşında ele alınmıştır. 
ET us- I 'susamak' (Clauson, 1972, s. 241a) fiilinden türemiş addır. EDPT ve DTS' de (Nadelyayev ve diğ., 1969, s. 616) yalnızca Eski Uygurca Heilkunde metniyle örneklendirilen bu ad Yakutçada anlam değişimine uğramadan varlığını sürdürmektedir.

54. ET usit- 'susatmak' (Clauson, 1972, s. 243a) > Yak. utat- I 'susamak, susuzluk çekmek, susuzluk hissetmek, susamış olmak, su içmek istemek’ (Pekarskiy, 1928, s. 3096), ayr. bkz. utat- (Sleptsov ve diğ., 1972, s. 446).

ET us- I 'susamak' (Clauson, 1972, s. 241a) fiilinin ettirgen biçimidir. Clauson sözcüğün olasılıkla güneydoğu grubundan Tarançı lehçesinde $u$ sat- olarak varlığını sürdürdüğü bilgisini verdiği bu ET fiil, Yakutçada da utat- olarak korunmuştur.

55. ET uzlan- 'ustalaşmak' (Clauson, 1972, s. 287b) > Yak. uustan- 'demirci tedarik etmek' (Pekarskiy, 1928, s. 3081), uustan- 'usta sahibi olmak, uzman sahibi olmak' (Sleptsov ve diğ., 1972, s. 448).

Clauson, ET'de ilk olarak $D L T$ 'de geçen bu fiili günümüz Türk dillerinden yalnızca Türkçe 'iyi, mükemmel olmak' ile tanıklamıştır. Pekarskiy'in anlam değişimiyle, Sleptsov ve diğg.' in ise ET $u z$ 'usta' (Clauson, 1972, s. 277b) sözcüğünün kök anlamına bağlı bir anlamla kaydettiği bu fiilin Yakutçada da varlığını sürdürdüğü görülmektedir.

56. ET ükäk 'kutu; kent surlarındaki burç' (Clauson, 1972, s. 105a) > Yak. ügex 'göçebe çadırlarının içindeki küçük dolap, göçebe çadırlarının girişindeki ambar; evin sol yarısındaki ardiye, küçük dolap; göçebe çadırlarının kuzey tarafında, uja oron'un karşısında yer alan, çadır sahibinin içindeki sandıklara ya da dolaplara giysilerini, dahası mallarını yerleştirdiği tahtalarla çevrili ufak depo; köşede duran keteğeriin oron ya da xayas oron biçiminde yapılmış, zaman zaman xayas bilirik (krş.) olarak da adlandırılan kanape -ki bu Rus izbelerinde kapıya yakın köşeye karşılık gelir-; genç kız ya da bekar erkek yatağı; göçebe çadırlarındaki yatak odası, depo, kız çocukların, çadır sahiplerinin kızlarının yatak odası olarak kullanılan depo; odacık, oturma odalarıyla ambar arasında yer alan ve kaymak tutması için kışın süt koyulan ufak bölme; yurt duvarlarında yer alan, süt ürünlerinin saklandığı boşluk, süthane' (Pekarskiy, 1928, s. 3105), ayr. bkz. ügex (Sleptsov ve diğ., 1972, s. 450).

ET ük- 'yığmak, biriktirmek' (Clauson, 1972, s. 100a) fiilinden türetilmiş olması muhtemel bu ad, Clauson (1972, s. 105a) tarafından yalnızca Tuvaca ügek 'küçük, kapalı bir alan, örn. köpek kulübesi, üzeri örtülü bir yük arabasının içi, nöbetçi kulübesi’ ve Kırgızca ükök 'sefer tası' verileriyle örneklendirilmiştir. Ancak sözcügün Yakutçada da ügex olarak varlığını sürdürdüğü görülmektedir.

57. ET üplä- 'çalmak' (Clauson, 1972, s. 11a) > Yak. üptee- 'mal mülk ya da para temin etmek’ (Pekarskiy, 1928, s. 3164).

ET'de tanıklanamayan fakat Tuvacada üp 'ganimet', Yakutçada üp olarak varlığını sürdüren * üp adından türemiş fiildir. Fiil Tuvacada üpte- olarak 'yağmalamak' (Clauson, 1972, s. 11a), Yakutçada üptee- olarak varlığını sürdürmektedir. 
58. ET üplän- 'yağmalanmak' (Nadelyayev ve diğ., 1969, s. 626) > Yak. üpten- 'mal mülk ya da para kazanmak’ (Pekarskiy, 1928, s. 3164), ayr. bkz. üpten- (Sleptsov ve diğ., 1972, s. 456).

EDPT'ye dahil edilmeyen ve $D L T$ ye ait olan bu veri, yukarıda verilen $\ddot{u} p l \ddot{a}$ - fiilinin dönüşlü çatısıdır. ET üptän- fiilinin günümüzde yalnızca Yakutçada varlığını sürdürdüğü görülmektedir.

59. ET ütläş- I 'delinmek; (savaşçılar) çarpışıp savaşmak' (Clauson, 1972, s. 59a) > Yak. üüttes- 'üüttee- I Fi. İşt. Bi.' (Sleptsov ve diğ., 1972, s. 460) $\rightarrow$ üüttee- I '1. delik açmak, delmek, matkap ile delmek; oymak; 2. sondaj yapmak' (Sleptsov ve diğ., 1972, s. 460).

Clauson (1972, s. 59a) ilk olarak DLT'de geçen bu fiili yalnızca Kazan Tatarcası ütleş'(iğne için) bir şeyin içerisinden doğru geçmek' verisiyle karşılaştırmıştır. Ancak fiilin Yakutçada da varlığını sürdürdüğü görülmektedir.

60. ET üzäki ‘üzerindeki’ (Clauson, 1972, s. 286a) > Yak. üöseegi, üöseeği, üüseeği, üöseeni, üüseeği 'yukarıdaki, üstteki, üst, yüce, yüksek, yukarıda yerleşik; âlî; yükseklik (yer seviyesinden yukarıda olma); yukarı dünya' (Pekarskiy, 1928, s. 3157), ayr. bkz. üöheeni (Sleptsov ve diğ., 1972, s. 456).

İlk olarak Manihaist Uygur metinlerinde görülen bu sözcük ET'de az sayıda metinle tanıklanabilmektedir. Clauson bu ET sözcüğü hiçbir çağdaş dille örneklendirmemiştir. Ancak sözcük Yakutçada varlığını sürdürmektedir. ET üzäki sözcüğünü türeten $+k I$ aitlik eki Yakutçada $-g I \sim-k I \sim-\eta I$ (Korkina ve diğ., 1982, s. 163, mad. 26) şeklinde varyantlaşmıştır.

\section{SONUÇ}

$\mathrm{Bu}$ incelemede VIII.-XIII. yüzyıllar arasını kapsayan Eski Türkçe döneminin Türkçe kökenli söz varlığ 1 ile Yakutçanın sözvarlığı karşılaştırılmıştır. Değerlendirmeye alınan verinin ünlüyle başlayan sözcüklerle sınırlandırıldığı incelemede toplam 60 Eski Türkçe sözcüğün Yakutça karşılığı üzerinde durulmuştur. Bu sözcükler diğer çağdaş Türk dillerinde kullanımdan düşen ya da Yakutçayla birlikte sadece birkaç Türk dilinde eskicil anlamlarını koruyarak varlığını sürdüren sözcüklerdir. İncelemenin sonuçları ET adgırlan-, adın, anala-, argur-, aşag, aşla- II, atla-, aytur-, ädgülä-, ädgür-, ädgürt-, ädläşs, ärgür-, erpä-, erpäg, erpäglä-, erpäş-, erpät-, ıdış-, ıdtur-, ıragu, igidtür-, irklä-, irklät-, irtäş-, ogullan-, ortunkl, ögirt-, ögirtür-, öglän-, udık, usak, üplän-, üzäki sözcüklerinin günümüzde yalnızca Yakutçada; ET agruk, agtur-, alkan-, arlg II, artak, asurt-, atın-, äkäç, ämig, äy II, ärlän-, äş- I, ätlän-, ıdala-, içlä-, ilintür-, irtä-, öçäs-, özlä-, udın-, urugla-, usıt-, uzlan-, ükäk, üpläve ütläş- sözcüklerinin ise Yakutçayla birlikte birkaç dilde daha varlığını sürdürdüğünü göstermektedir.

Finansal Destek: Yazar bu çalışma için finansal destek almamıştır. 


\section{KAYNAKÇA}

Alekseyev, A. N. (1996). Drevnyaya Jakutiya - Neolit i epoxa bronzı. Novosibirsk: İzdatel'stvo instituta arxeologii i etnografii.

Böhtlingk, O. (1851). Über die Sprache der Jakuten. Saint-Peterburg: Buchdruckerei der Kaiserlichen Akademie der Wissenschaften.

Civelek, Ö. (2016). Dindışı Eski Uygurca metinlerin karşılaştırmalı sözvarllğı. İstanbul: Türk Dil Kurumu Yayınları.

Clauson, G. (1972). An etymological dictionary of pre-thirteenth-century Turkish. Oxford: Oxford University Press.

Devlet, N. (1997). Sibirya'daki halkların demografik ve ekonomik potansiyelleri. Emine Gürsoy-Naskali (Ed.), Sibirya Araştırmaları içinde (s. 25-46). İstanbul: Simurg.

Erdal, M. (1991). Old Turkic word formation I-II. Wiesbaden: Otto Harratsowitz.

Gogolev, A. I. (1993). Jakuty. Problemy etnogeneza i formirovanija kul'tury. Yakutsk: Izdatel'stvo JaGU. Hayit, Baymirza (1985). Yakut (Saha) Türkleri. Türk Kültürü Araştırmaları, 23, 1-2.

Kałużyński, S. (1995). Iacutica. Warszawa: Dialog.

Karahan, A. (2010). Divanu Lügati 't-Türk'e göre Türk lehçe bilgisi. Ankara: Türk Dil Kurumu Yayınları.

Killi, G. (1997). Kuzey ve Güneydoğu Sibirya Türklüğünün (Saha, Tuva, Hakas, Altay) Diline Fonolojik Açıdan Bir Bakış. Sibirya Araştırmaları, Emine Gürsoy-Naskali (Ed.), Sibirya Araştırmaları içinde (s. 57-68). İstanbul: Simurg.

Kirişçioğlu, M. F. (1999). Saha (Yakut) Türkçesi grameri (2. bs). Ankara: Türk Dil Kurumu.

Konstantinov, İ. V. (2003). Proisxojdenie yakutskogo naroda i ego kul'turı. Yakutsk: Akademiya nauk respubliki saxa (yakutiya).

Korkina, E.İ., E.İ. Ubryatova, L.N. Xaritonov, N.E. Petrov. 1982. Grammatika sovremennogo yakutskogo literaturnogo yazıka. Moskva: Nauka.

Krueger, J. R. (1962). Yakut manual. Indiana: Indiana University Publications.

Levin, G. G. (2001). Lexiko-semantiçeskie paralleli orxonsko-tyurskogo i yakutskogo yazıkov: v sravnitel'nom plane s altayskim, xakasskim, tuvinskim yazıkami. Novosibirsk: Nauka.

Li, Y.-S. (1999). Türk dillerinde akraballk adları. İstanbul: Simurg.

Malov, S. E. (1952). Yeniseyskaya pis'mennosti Tyurkov: tekstı i perevodı. Moskva/Leningrad: İzdatel'stvo Akademii Nauk SSSR.

Nadelyayev, V. M., Nasilov, D. M., Tenişev, E. R., Şçerbak A.M. (1969). Drevnetyurskiy slovar'. Leningrad: Nauka.

Nasilov, D. M. (1997). Sibirya Türk Halkları (Etnik Azınlıkları) ve Dilleri. Emine Gürsoy-Naskali (Ed.), Sibirya Araştırmaları içinde (s. 51-55), İstanbul: Simurg.

Okladnikov, A. P. (1955). İstoriya yakutskoj ASSR. Tom 1: Yakutiya do prisoedineniya $k$ russkomu gosudarstvu. Moskva-Leningrad: İzdatel'stvo akademii nauk SSSR.

Pakendorf, B. (2007). Contact in the prehistory of the Sakha (Yakuts): Linguistic and genetic perspectives. Utrecht: LOT.

Pekacar, B. Y. (2012). Divânü Lügati’t-Türk’teki kültür kelimeleri ile Saha Türkçesinin kelime hazinesinin karşılaştırılması. (Yüksek Lisans Tezi). Gazi Üniversitesi Sosyal Bilimler Enstitüsü, Ankara.

Pekarskiy, E. K. (1917). Slovar'yakutskogo yazlka I. Petrograd': İmperatorskoy Akademii Nauk.

Pekarskiy, E. K. (1927). Slovar' yakutskogo yazıka II. Leningrad: Akademii nauk soyuza sovetskix sotsialistiçeskih respublik. 
Pekarskiy, E. K. (1925). Slovar' yakutskogo yazıka III. Leningrad: Akademii nauk soyuza sovetskix sotsialistiçeskih respublik.

Pekarskiy, E. K. (1928). Slovar' yakutskogo yazıka IV. Leningrad: Akademii nauk soyuza sovetskix sotsialistiçeskih sespublik.

Poppe, N. (1960). Vergleichende grammatik der altaischen sprachen. Wiesbaden: Otto Harrassowitz.

Radloff, V. (1893-1899-1905-1911). Opyt slovarya tyurkskih nareçiy I-IV. Sankt Peterburg: İmperatorskiy akademii nauk.

Ramstedt, G. J. (1957). Einführung in die altaische Sprachwissenschaft II: Formenlehre. Helsinki: Suomalais-Ugrilainen Seura.

Röhrborn, Klaus (1977). Uigurisches Wörterbuch. Lieferung 1: a-agrı. Wiesbaden: Franz Steiner Verlag.

Röhrborn, Klaus (1979). Uigurisches Wörterbuch. Lieferung 2: agrlglan- - anta. Wiesbaden: Franz Steiner Verlag.

Röhrborn, Klaus (1981). Uigurisches Wörterbuch. Lieferung 3: anta-asankä. Wiesbaden: Franz Steiner Verlag.

Röhrborn, Klaus (1994). Uigurisches Wörterbuch. Lieferung 5: ayatıl- - ämgäklig. Wiesbaden: Franz Steiner Verlag.

Röhrborn, Klaus (1998). Uigurisches Wörterbuch. Lieferung 6: ämgäksin- - ärøäk. Wiesbaden: Franz Steiner Verlag.

Röhrborn, Klaus (2010). Uigurisches Wörterbuch, Sprachmaterial der vorislamischen türkischen Texte aus Zentralasien, Neubearbeitung, I. Verben, Band 1: ab- - äzüglä-, Stuttgart: Franz Steiner Verlag.

Schönig, K. (1999). The internal division of modern Turkic and its historical implications. Acta Orientalia Academiae Scientiarum Hungaricae, 52, 63-95.

Sleptsov, P. A., Korkina, E. İ., Koryakina, K. N., Kılatçanov, S. P. Nikiforov, G. A. Okoneşnikov, Petrov, N. E., Skrıbıkin, N. V., Haritonov, L. N. (1972). Yakutsko-russkiy slovar'. Moskva: Sovetskaya Entsiklopediya.

Şirobokova, N. N. (1977). Ob otnoşenii yakutskogo yazıka k yazıkam drevnetyurskix pamyatnikov. Issledovaniya po yazıkam narodov Sibiri-sbornik nauçnıh trudov, 108-116.

Şirobokova, N. N. (2001). Istoriçeskoe razvitie yakutskogo konsonantizma. Novosibirsk: Nauka.

Şirobokova, N. N. (2005). Otnoşenie yakutskogo yazıka k tyurkskim yazıkam yujnoy sibirii. Novosibirsk: Nauka.

Tekin, T. (1995). Türk dillerinde birincil uzun ünlüler. Ankara: Simurg.

Türkçe Sözlük (2005). Ankara: Türk Dil Kurumu.

Ubryatova, E. İ. (1960). Yakutskii yazık v ego otnoşenii k drugim tyurkskim yazıkam, a takje k yazıkam mongol'skim i tunguso-man'çyurskim, İzd.-Vo Vost. Lit., 258-271.

Yıldız, H. (2006). Yakutça ve eski Türkçenin söz varlığı üzerine bir karşılaştırma. Sibirische Studien, $1(2), 177-221$.

Yıldız, H. (2007a). Orhon Türkçesi ile Yakutçanın söz varlığı ve sözyapımı bakımından karşılaştırılması. (Yüksek Lisans Tezi). Anadolu Üniversitesi Sosyal Bilimler Enstitüsü, Eskişehir.

Yıldız, H. (2007b). Orhon yazıtlarından Yakutça ve Dolgancaya ulaşan eskicil sözvarlığı. Sibirische Studien, 2(1), 13-40.

Yıldız, H. (2011). Yakutçayla tanıklanabilen hapax legomenon'lar. International Journal of Central Asian Studies, 15, 21-42. 
Yıldız, H. (2014). Yakutçayla tanıklanabilen hapax legomenon'lar II: Ünsüzle başlayan hapax'ların durumu. Siberian Studies, 2(5), 37-54.

Yıldız, H. (2015). Eski Türkçe ile Yakutçanın sözvarlığının ünlüyle başlayan sözcükler bakımından karşılaştırılması. (Doktora Tezi). Yıldız Teknik Üniversitesi Sosyal Bilimler Enstitüsü, İstanbul.

Yudahin, K. K. (1998). Kırgız Sözlüğü II: K-Z. (Abdullah Taymas, Çev.). Ankara: Türk Dil Kurumu. 